\title{
Persistent Enhancement of Hippocampal Network Connectivity by Parietal rTMS Is Reproducible
}

\author{
ํㅣㄹ Michael Freedberg, ${ }^{1,2}$ Jack A. Reeves, ${ }^{1}$ Andrew C. Toader, ${ }^{1}$ Molly S. Hermiller, ${ }^{6}$ Joel L. Voss, ${ }^{3,4,5,6}$ \\ and ${ }^{(1)}$ Eric M. Wassermann ${ }^{1}$
}

https://doi.org/10.1523/ENEURO.0129-19.2019

\begin{abstract}
${ }^{1}$ National Institute of Neurological Disorders and Stroke, Bethesda, MD 20892, ${ }^{2}$ Henry M. Jackson Foundation for the Advancement of Military Medicine, Bethesda, MD 20817, ${ }^{3}$ Northwestern University Interdepartmental Neuroscience Program, Northwestern University, Chicago, Illinois, ${ }^{4}$ Ken and Ruth Davee Department of Neurology, Feinberg School of Medicine, Northwestern University, Chicago, Illinois 60611, ${ }^{5}$ Department of Medical Social Sciences, Feinberg School of Medicine, Northwestern University, Chicago, Illinois 60611, and ${ }^{6}$ Northwestern University Interdepartmental Neuroscience Program, Northwestern University, Chicago, Illinois 60611
\end{abstract}

\begin{abstract}
Wang et al. (2014) found that that five daily sessions of repetitive transcranial magnetic stimulation (rTMS) of the posterior parietal cortex (PPC) significantly increased functional connectivity (FC) in a network centered on the hippocampus, and caused a correlated increase in memory performance. However, this finding has not been reproduced independently and the requirement for five sessions has not been validated. We aimed to reproduce the imaging results of this experiment, focusing on hippocampal FC changes and using fewer days of $r$ TMS. We measured resting state FC before and after three $(N=9)$ or four $(N=6)$ consecutive daily PPC rTMS sessions, using similar delivery parameter settings as Wang et al. (2014). Eight subjects received $3 \mathrm{~d}$ of $r$ TMS delivered to the vertex as a control. We employed whole-brain and hypothesis-based statistical approaches to test for hippocampal FC changes. Additionally, we calculated FC in 17 brain networks to determine whether the topographic pattern of FC change was similar between studies. We did not include behavioral testing in this study. PPC, but not vertex, rTMS caused significant changes in hippocampal FC to the same regions as in the previous study. Brain-wide changes in hippocampal FC significantly exceeded changes in global connectedness, indicating that the effect of PPC rTMS was specific to the hippocampal network. Baseline hippocampal FC, measured before receiving stimulation, predicted the degree of rTMS-induced hippocampal FC as in the previous study. These findings reproduce the imaging findings of Wang et al. (2014) and show that FC enhancement can occur after only three to four sessions of PPC rTMS.
\end{abstract}

Key words: fMRI; functional connectivity; hippocampus; TMS

\section{Significance Statement}

One of the most striking recent findings in the area of neuromodulation is that of Wang et al. (2014), who reported that posterior parietal cortex (PPC) stimulation increased functional connectivity (FC) in a network related to declarative memory and centered on the hippocampus, a result with great potential experimental and clinical utility. We used a similar paradigm, with shorter treatment duration and reproduced the effects on connectivity, including specificity for the hippocampal network and dependence on the magnitude of baseline hippocampal connectivity. These results confirm and extend the initial finding and validate the technical approach.

\section{Introduction}

Enhancing memory in patients and healthy individuals is a potential application of repetitive transcranial mag-

Received March 30, 2019; accepted September 17, 2019; First published October 7, 2019.

The authors declare no competing financial interests. netic stimulation (rTMS). Network connectivity modulation with non-invasive brain stimulation has been studied mostly in motor and procedural learning networks (Mu- 
ellbacher et al., 2002; Baraduc et al., 2004; Wilkinson et al., 2010, 2015; Hotermans et al., 2008; Rosenthal et al., 2009; lezzi et al., 2010; Teo et al., 2011) and the effects have not been shown to last longer than minutes or hours (Thut and Pascual-leone, 2010). The declarative memory system, on the other hand, has been less explored with rTMS, despite the fact that declarative memory deficits are among the most common and debilitating problems in neurology (Vakil, 2005; Nestor et al., 2006). Wang et al. (2014) increased declarative memory and resting hippocampal network functional connectivity (FC) by delivering multiple-session rTMS to individualized targets in the posterior parietal cortex (PPC), which is connected with the hippocampus via the retrosplenial and paraphippocampal cortices (Mesulam et al., 1977; Cavada and Goldman-Rakic, 1989). The FC increase and memory improvement persisted for $24 \mathrm{~h}$ after the final rTMS session and, with reduced strength, for up to approximately two weeks (Wang et al., 2014; Wang and Voss, 2015).

The Wang et al. (2014) findings are a dramatic demonstration of physiologic engagement of a specific brain target with correlated behavioral improvement and are, in this respect, unique in the noninvasive neuromodulation field. However, concern has grown over the rate of false positives in functional neuroimaging (Poldrack et al., 2017) and noninvasive neuromodulation (Nahas et al., 2008; Héroux et al., 2015), resulting in calls for reproduction of results. For example, Héroux et al. (2015) found that only between $45 \%$ and $60 \%$ of experienced researchers were able to reproduce a rTMS effect.

In this study, we used a similar paradigm to that of Wang et al. (2014), with identical targeting procedures and stimulation parameter values, but with fewer stimulation sessions and without memory testing. We also preprocessed the data somewhat differently and used vertex stimulation, instead of subthreshold or motor stimulation, as our control condition. Although the original researchers collaborated on this study and shared unpublished data and techniques with us, all data collection, implementation, and analysis were performed independently.

\section{Materials and Methods}

\section{Subjects}

Twenty-three healthy adults (nine females; age = 19-31 years), free of neurologic or psychiatric disorders or medications acting on the central nervous system,

This work was supported in part by the Intramural Research Program of the National Institutes of Health, NINDS, and the Center for Neuroscience and Regenerative Medicine Grant CNRM-70-3904. J.L.V. and M.S.H. are supported by grants from the National Institutes of Mental Health (R01MH106512) and Neurological Disorders and Stroke (T32NS047987).

Correspondence should be addressed to Michael Freedberg at michael.freedberg@nih.gov.

https://doi.org/10.1523/ENEURO.0129-19.2019

Copyright (C) 2019 Freedberg et al.

This is an open-access article distributed under the terms of the Creative Commons Attribution 4.0 International license, which permits unrestricted use, distribution and reproduction in any medium provided that the original work is properly attributed. participated in the study. Fifteen received active rTMS delivered to the PPC and eight underwent a control procedure with identical stimulation applied to the vertex. All subjects reported being right-handed and passed screening for contraindications to TMS (Rossi et al., 2009) and MRI. Written informed consent was obtained and the study was approved by the local Institutional Review Board.

\section{Procedures}

All subjects underwent, in order, baseline scanning, three or four consecutive daily rTMS sessions, and a post-rTMS scan. Baseline scanning included an anatomical localizer, structural scan (for functional scan co-localization with anatomy, and neuro-navigation), a single resting state scan, and diffusion tensor imaging (not reported here). Nine subjects received three consecutive daily sessions of rTMS delivered to the PPC, six received four daily PPC sessions, and eight received three daily sessions of identical rTMS delivered to the vertex (see rTMS, below). The interval between rTMS sessions was $\sim 24 \mathrm{~h}$.

Twelve of our PPC subjects participated in a separate study to find the minimum number of days required to produce a conservative criterion change in hippocampal FC. We found no measurable difference in response between subjects receiving 3 and $4 \mathrm{~d}$ of rTMS $(W=36, p=$ $0.327,95 \% \mathrm{Cl}[-0.074333,0.210993])$, so all were included here. The number of stimulation sessions in this study differed from Wang et al. (2014), who delivered stimulation on five consecutive days.

Unlike Wang et al. (2014), we used rTMS at the vertex, which produces auditory and somatosensory stimulation, but no significant changes in FC (Jung et al., 2016), as our control condition (see Discussion). Subjects underwent the first rTMS session within $36 \mathrm{~h}$ of baseline scanning. The second MRI session occurred on the day after the final rTMS session and within $3 \mathrm{~h}$ of the time of day of the first scanning session. Subjects were blind to the specific intent of the study and the stimulation condition.

\section{fMRI acquisition and preprocessing}

MRI was performed on a Siemen's Magnetom 3T scanner using a 16-channel head coil with foam padding to prevent head movement. Subjects were fitted with earplugs and supplied with headphones to protect hearing. During resting scans, subjects were instructed to lie still with their eyes open.

Blood oxygen level-dependent (BOLD) data were recorded with a T2*-weighted gradient-echoplanar imaging sequence (EPI: TR $=2000 \mathrm{~ms}$, TE $=27 \mathrm{~ms}$, flip angle = $90^{\circ}, 36$ transversal contiguous interleaved slices per volume, 3.0 slice thickness, FOV $22 \times 22 \mathrm{~cm}$, matrix size 64 $\times 64$, voxel size $=3.4 \times 3.4 \times 3.0 \mathrm{~mm}$; scan length $\sim 6.8$ $\mathrm{min})$. We acquired structural images with a magnetizationprepared rapid gradient echo sequence (MPRAGE; TR = $2530 \mathrm{~ms}$, TE $=3.03 \mathrm{~ms}, 176$ slices per volume, $1-\mathrm{mm}$ thickness, $\mathrm{FOV}=25.6 \times 25.6 \mathrm{~cm}^{2}, 256 \times 256$ acquisition matrix, voxel size $=1.0 \mathrm{~mm}$ isotropic, 206 volumes, 6.83 $\min )$. 
We processed the images with analysis of functional images (AFNI; Cox, 1996; RRID:SCR_005927) software. The first five volumes of 206 were removed to ensure that magnetization was stabilized. Preprocessing included motion correction, slice-timing correction to the first slice, functional/structural affine co-registration to Talairach space (TT_N27; Talairach and Tournoux, 1988), resampling to $2.0 \mathrm{~mm}$ isotropic voxel resolution, spatial smoothing using a 4-mm full-width half maximum (FWHM) Gaussian kernel, and linear detrending. We then scaled each voxel time series to a mean of 100 , with a range of 0-200 and regressed head motion from each voxel time series using the mean and derivatives of six parameter estimates (pitch, roll, yaw, and rotation around each axis). Unlike Wang et al. (2014), we did not bandpass filter our data because test-retest reliability increases as the high pass cutoff is raised and even eliminated (Shirer et al., 2015). However, we achieved a high-pass filter via linear detrending using a 2nd or 3rd order polynomial, depending on the subject. We used spatial smoothing, which was omitted by Wang et al. (2014). Finally, frames which included movement displacement $>0.3 \mathrm{~mm}$ were censored before statistical analysis to prevent inflated correlations (Power et al., 2012). We used a threshold of $0.3 \mathrm{~mm}$ of average head displacement across all frames, including censored ones, during any scan to exclude subjects (one subject).

We reprocessed and reanalyzed data from Wang et al. (2014), which were acquired on a Siemens 3T TIM Trio with a 32-channel head coil. Structural (MPRAGE T1weighted scans, TR $=2400 \mathrm{~ms}$, TE $=3.16 \mathrm{~ms}$, voxel size $=1 \mathrm{~mm}^{3}, \mathrm{FOV}=25.6 \mathrm{~cm}$, flip angle $=8^{\circ}, 176$ sagittal slices) and functional whole-brain BOLD EPI (TR $=2500$ $\mathrm{ms}, \mathrm{TE}=20 \mathrm{~ms}$, voxel size $=1.72 \times 1.72 \times 3 \mathrm{~mm}^{3}$, FOV $=22 \mathrm{~cm}$, flip angle $=80^{\circ}, 244$ volumes, $10.2 \mathrm{~min}$ ). We handled them identically to our own data, but resampled to $1.5-\mathrm{mm}$ isotropic voxel resolution.

\section{rTMS targeting}

We based our targeting procedure on Wang et al. (2014) who chose the PPC subregion that was maximally connected to the hippocampus in each subject. They searched the anterior/middle hippocampus for the voxel with maximal FC to the PPC and chose the PPC location where this $\mathrm{FC}$ was strongest as the stimulation target. We applied a similar technique. For subjects receiving PPC stimulation, we guided rTMS to the PPC location with maximum FC to a seed location in the hippocampus. In each subject, the PPC target search volume was a sphere of $15-\mathrm{mm}$ radius, cut to exclude non-brain voxels, around Talairach location $x=-47, y=-68, z=+36$, which included the supramarginal and angular gyri. The search for the hippocampal seed voxel involved two approaches, both employing automated scripts. For the first approach (12 subjects), we chose the maximally connected hippocampal voxel from six preselected locations along the longitudinal aspect of the hippocampus in TalairachTournoux space (seed 1: $x=-26, y=-10, z=-17$; seed 2: $x=-22, y=-16, z=-13$; seed 3: $x=-30, y=-17, z$ $=-14$; seed $4: x=-30, y=-22, z=-12$; seed $5: x=-30$,
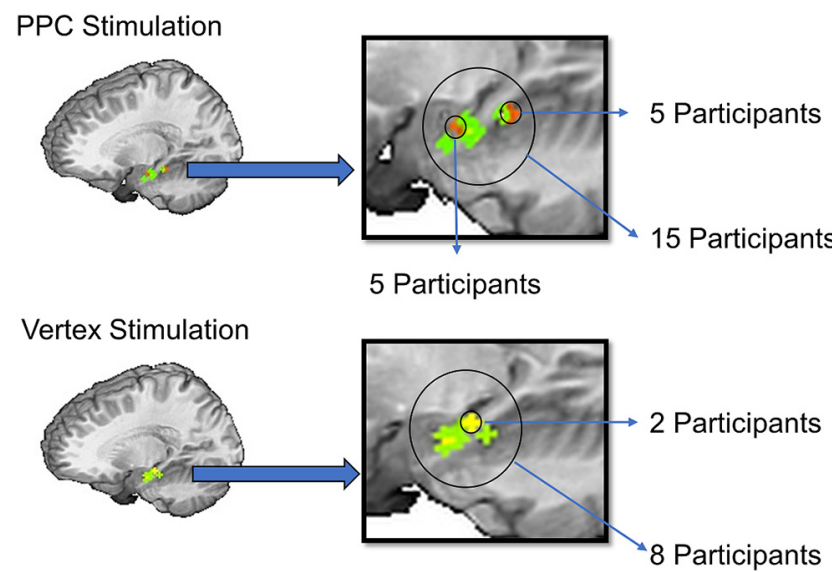

Figure 1. Seed locations from PPC (top; $N=15$ ) and vertex groups (bottom; $N=8$ ).

$y=-27, z=-9$; seed $6: x=-30, y-32, z=-6)$. This deviated from the seeding procedure of Wang et al. (2014), who sampled only from the anterior/middle hippocampus. In the second approach (three subjects), we selected the maximally connected one of 97 preselected voxels in the anterior hippocampus. These included hippocampal voxels within $15 \mathrm{~mm}$ of the Talairach coordinates identified in Wang et al. (2014; $x=-24, y=-18, z$ $=-18$ ). This approach was intended to provide wider sampling within the hippocampus. Figure 1 illustrates the seed locations for each subject. In both approaches, we created a 3-mm radius sphere around the coordinates of each voxel in the search and computed an average time series using the voxels in that sphere. We then searched the PPC sphere for the voxel with maximum correlation with the hippocampal seed, marked its location in standard space, and then back-transformed the location into subject space using the inverse matrix of the original affine transformation. Next, this location was transformed into a 3-mm radius sphere and overlaid on the subject's structural MRI for rTMS targeting with the Brainsight frameless stereotaxic system. For the PPC target, a stimulation trajectory was created in Brainsight, so that the plane of the coil was tangential to the scalp and the induced current field was oriented perpendicular to the long axis of the gyrus containing the stimulation target. For control stimulation, we located the vertex using the 10-20 International system (Steinmetz et al., 1989), and held the coil tangential to the scalp with the junction of the coil lobes in the sagittal axis.

\section{rTMS}

TMS was delivered with a MagStim Rapid ${ }^{2}$ stimulator through a Double Airfilm coil. Wang et al. used a Nexstim eXimia NBS 4.3 air-cooled, MRI-guided system and a 70-mm figure eight coil. rTMS intensity was referenced to the individual motor evoked potential threshold, which was determined in the current experiment immediately before the first rTMS session using the TMS Motor Threshold Assessment Tool (MTAT 2.0; http://www.clinicalresearcher.org/software.htm). Stimulation parameter settings for PPC and vertex stimulation were identical to 
those of Wang et al. (2014), i.e., 2-s trains at $20 \mathrm{~Hz}(40$ pulses per train) with an intertrain interval of $28 \mathrm{~s}$, at $100 \%$ of resting motor threshold (RMT). There were 40 trains, 1600 pulses, and a duration of 20 min per session.

\section{FC calculations and voxel-wise analysis}

For all hippocampal FC analyses, we conducted the following steps: Preprocessed data from the prestimulation and poststimulation resting state scans were seeded at the hippocampal location maximally connected with the PPC in the prestimulation scan, the area found for rTMS targeting. We created a 3-mm radius sphere around this location and averaged the BOLD time series of all voxels within it to derive a single hippocampal time series. Pearson's $r$ values were then computed for the correlation between this time series and that from every voxel in the rest of the brain. Finally, all $r$ values were $r$-to-z Fisher transformed to form a final connectivity metric $\left[z_{(r)}\right]$ across voxels for each scan.

\section{Whole brain changes in hippocampal network FC and comparison to Wang et al. (2014)}

To identify areas where PPC rTMS caused significant changes in hippocampal FC, and to see whether they were in the same areas reported by Wang et al. (2014), $z_{(r)}$ values for each subject and time point, prestimulation and poststimulation, were fed into AFNl's $3 d t t e s t++$ command for comparison. A group mask excluded ventricles and white matter. The results were false discovery rate (FDR) corrected at $q=0.05$. We applied Bonferroni corrected post hoc tests to significant clusters in regions where Wang et al. (2014) reported significantly greater hippocampal FC increases with active compared to sham rTMS. These included the precuneus/retrosplenial, fusiform, lateral parietal, and superior parietal areas $(\alpha=$ $0.05 / 4=0.0125$ ). Wilcox rank-sum testing was used for significance testing since these data were non-normally distributed.

\section{Hypothesis-based comparison to the Wang et al. (2014) results}

We performed this analysis to see whether PPC rTMS in the current study caused significant increases in hippocampal FC within a mask of regions showing significant hippocampal FC change in the reanalyzed data of Wang et al. (2014). To determine this region-of-interest, we searched for areas of the posterior left hemisphere that showed a significant increase in hippocampal FC after active rTMS, relative to sham, and calculated $z_{(r)}$ values as described above. For each subject in the data set of Wang et al. (2014), the prestimulation correlation map was subtracted from poststimulation map, and the pre-sham map from the post-sham map. We then fed these subtractions into AFNl's 3dttest + + command for contrast. Like Wang et al. (2014), we applied a cluster size threshold of 290 voxels and identified a cluster encompassing the left precuneus and medial occipital lobe (left precuneus/occipital cortex; LPOC). We created a mask from these regions by applying the 3dclust command in AFNI and resampling the mask to the geometry of our own dataset (2-mm isotropic voxels). To account for variability across sub- jects, we dilated the mask by three voxels while restricting voxels to the left hemisphere. The pattern of results did not change based on the dilation of the mask. Finally, using the present data, we calculated prestimulation and poststimulation hippocampal FC in these regions and contrasted the resulting prestimulation and poststimulation $z_{(r)}$ values using a Wilcox rank-sum test, to look for a significant PPC rTMS-related change in FC between the hippocampus and the LPOC region, like that reported by Wang et al. (2014).

We also calculated the change in hippocampus-LPOC FC with vertex rTMS. Here, we used the hippocampal seed that was maximally connected with the PPC target at baseline, and the same automated script applied to the PPC subjects, to avoid potential bias in the selection of seeds. To determine whether changes in hippocampal FC with the LPOC mask were specific to PPC stimulation, we compared the rTMS-related change in hippocampusLPOC FC between groups with the Mann-Whitney test. Additionally, to determine whether our results were affected by differences in sample size between groups, we performed a permutation test using matched sample sizes. This was performed by subtracting the mean FC change of the vertex group from the mean FC change in eight subjects randomly selected from the PPC group. This was performed 1000 times to form a distribution of possible outcomes, which we then compared to the observed mean difference.

\section{Specificity analysis}

To gauge the specificity of the Wang et al. (2014) effect on FC, we compared the changes in hippocampal FC and global connectedness (GC) occurring in the LPOC mask (LPOC-GC) with PPC rTMS. To calculate LPOC-GC, we found Pearson's $r$ values for each voxel in the brain for the correlation of its time series with those of every other voxel. Next, we calculated the mean of all of the $r$ values for each voxel within the LPOC mask (Gotts et al., 2012). The mean $r$ values were then $r$-to-z Fisher transformed to create a GC value for each voxel. Finally, all voxel GC values in the LPOC mask were averaged.

As an additional control, we calculated the change in FC between the left dorsolateral prefrontal cortex (DLPFC) and the LPOC mask with the expectation that PPC stimulation would not significantly enhance FC between these regions. We created the DLPFC seed by forming a 3-mm radius sphere around Talairach and Tournoux location $x=$ $-41, y=44, z=5$, a peak area of activation found during procedural learning (Poldrack et al., 2001). The mean time series from this sphere was then compared with that from every voxel in the LPOC mask. Finally, we took the mean of all r-to-z transformed values in the LPOC mask. Wilcox rank-sum tests were performed to determine whether the hippocampal-LPOC FC change differed significantly from the DLPFC-LPOC FC and LPOC-GC changes.

\section{Comparison of topographic changes}

We assessed the topographic pattern of hippocampal FC changes from PPC stimulation by calculating the change in hippocampal FC with 17 segregated networks (Yeo et al., 2011) using AFNl's 3dBrickStat command. We 
also calculated within-network GC for this analysis using the time series of all voxels in each of the 17 networks. GC for each network was calculated as the mean $z_{(r)}$ value across all voxels in that network. We then compared the hippocampal FC and GC changes. The same steps were performed using the pre- to post-active stimulation data from Wang et al. (2014). We performed hippocampal-FC to GC comparisons for each study with one-sample, twotailed, $t$ tests, since these data were normally distributed.

Finally, to test the hypothesis that the magnitude of hippocampal FC changes across networks were correlated across studies, we conducted a simple correlation analysis to test this hypothesis $(\alpha=0.05)$.

\section{Correlation between baseline hippocampal FC and rTMS-induced changes in FC among hippocampal network nodes}

The purpose of this analysis was to determine whether we could reproduce the finding of Wang et al. (2014), that baseline hippocampal FC predicted the degree of PPC rTMS-induced change in hippocampal FC among brain areas. We first found clusters of voxels in our data where rTMS produced a significant increase in hippocampal FC at a threshold of $p<0.01$, with no spatial extent threshold. Like Wang et al. (2014), we applied a liberal threshold to include a range of change values. This resulted in 183 significant clusters, which we then divided into automated anatomic labeling (AAL; Tzourio-Mazoyer et al., 2002)-defined anatomic regions and all regions with $>15$ voxels were included in the analysis. The 15-voxel threshold was applied to ensure that each cluster contained enough voxels to calculate a reliable mean time series. This resulted in 95 clusters. We then formed a correlation matrix for each subject and time point by comparing the mean time series of each cluster with that of each other cluster (3dNetCorr). Next, we averaged the correlation matrices within each time point across subjects and subtracted the prestimulation correlation matrix from the poststimulation matrix. This resulted in a single matrix, which we sorted by baseline hippocampal FC. Then, to determine whether baseline hippocampal FC predicted the rTMS-induced change in FC, we plotted the baseline hippocampal FC of each cluster against the mean change in FC between that cluster and every other cluster. Finally, to determine whether these changes were specific to FC with the hippocampus, we performed the same analyses, but replaced hippocampal FC with GC for each cluster. Additionally, we re-sorted these matrices by region to reveal, qualitatively, areas where hippocampal nodes and nodes that increased in GC, showed the highest change in FC.

\section{Statistical analyses}

All analyses were conducted using $\mathrm{R}$ software. Shapiro-Wilks tests of normality were conducted before each analysis. Table 1 lists the specifications of each test, including critical values, the data used in each test, and confidence intervals. In the Results, an alphabetic code is listed with each test linking it to additional details in Table 1.

\section{Results}

The interval between rTMS sessions was $23.9 \pm 3.0 \mathrm{~h}$ for the PPC group and $24.3 \pm 2.7 \mathrm{~h}$ for the vertex group (non-significant; Table 1, a, $W=36, p=0.327,95 \% \mathrm{Cl}$ $[-0.0743,0.2110])$. Head motion, calculated as average head frame displacement in six directions, did not significantly differ between scans (prestimulation vs poststimulation; Table 1, b, $V=167, p=0.194,95 \% \mathrm{Cl}[-0.0743$, $0.2110]$ ) or groups (parietal vs vertex; Table $1, \mathrm{c}, W=$ $199.5, p=0.350,95 \% \mathrm{Cl}[-0.0225,0.0096])$. The same was true for the number of censored TRs during denoising (prestimulation vs poststimulation; Table $1, \mathrm{~d}, V=118.5$, $p=0.155,95 \% \mathrm{Cl}[-0.9999,6.5000] ;$ parietal vs vertex; Table 1, e, $W=218.5, p=0.604,95 \% \mathrm{Cl}[-3.0000$, $0.00004])$. Average head displacement was $0.089 \pm 0.005$ $\mathrm{mm}$ per frame. The average number of censored TRs per scan was $5.348 \pm 1.561$.

Figure 2 shows regions that changed in $\mathrm{FC}$ with the hippocampus (FDR corrected, $q=0.05$ ) in the current sample. These changes were all increases. PPC rTMS produced significant increases in hippocampal FC in all of the areas reported by Wang et al. (2014), including left retrosplenial cortex (Table 1, f, $V=7, p=1.16 \times 10^{-3}$, $95 \% \mathrm{Cl}[0.0654,0.2590])$, left fusiform gyrus (Table $1, \mathrm{~g}, \mathrm{~V}$ $\left.=4, p=4.27 \times 10^{-4}, 95 \% \mathrm{Cl}[0.0951,0.2132]\right)$, left lateral PC (Table 1, h, $V=1, p=1.22 \times 10^{-4}, 95 \% \mathrm{Cl}$ $[0.0777,0.2034]$ ), left superior PC (Table 1, i, $V=2, p=$ $1.83 \times 10^{-4}, 95 \% \mathrm{Cl}[0.0815,0.2294]$; all results Bonferroni corrected).

In our reanalysis of the Wang et al. (2014) data, the LPOC region of interest showed significantly increased FC with the hippocampus after active rTMS, relative to sham. In the current sample, we also found that PPC rTMS caused significant increases there (Table 1, j, $V=$ 95, $p=0.048,95 \% \mathrm{Cl}[0.0013,0.2053]$; Fig. 3A). This increase $\left[z_{(r)}=0.20 \pm 0.04\right.$; mean $\left.{ }_{(S E M)}\right]$ was larger than, and opposite in direction to, the mean change after vertex rTMS $\left(z_{(r)}=-0.08 \pm 0.06\right.$; Fig. $\left.3 A\right)$. The changes in the PPC rTMS group were significantly greater than the changes in the vertex group (Table 1, k, $W=93, p=$ $0.034,95 \% \mathrm{Cl}[0.0195,0.3257])$. Vertex stimulation did not cause changes in hippocampal-LPOC FC (Table 1, I, $V=7, p=0.148,95 \% \mathrm{Cl}[-0.055,0.2357])$. Resampling the group differences in hippocampal-LPOC FC in 1000 matched groups of eight subjects showed no instances where changes were greater in the vertex group, including those bounded by $95 \%$ of the distribution (Table 1, m, observed mean $=0.1795,95 \%$ of distribution $[0.02513$, 0.03392]; Fig. 4). Thus, it is unlikely that our results were driven by differences in sample size between groups. Whole-brain analyses of hippocampal FC changes in the vertex group did not reveal any significant clusters (all $p>$ 0.05). The same was true when measuring FC from the vertex stimulation site.

In the current data, DLPFC-LPOC FC did not increase significantly after PPC rTMS (Table $1, \mathrm{n}, V=81, p=$ $0.2524,95 \% \mathrm{Cl}[-0.0344,0.1270]$; Fig. $3 A$ ), but the DLPFC-LPOC FC change did not differ significantly from the hippocampal-LPOC FC change (Table 1, o, $V=75, p$ $=0.4212,95 \% \mathrm{Cl}[-0.0636,0.1593])$, nor did LPOC-GC 
Table 1. Statistics table indicating the results of all analyses

\begin{tabular}{|c|c|c|c|c|c|c|c|c|c|c|}
\hline Manuscript & Figure & Sample & Data type & Data structure & Type of test & $\begin{array}{c}\text { Multiple } \\
\text { comparison } \\
\text { correction }\end{array}$ & Program & Statistics & $p$ values & Confidence intervals \\
\hline $\bar{a}$ & & Current & $\begin{array}{l}\text { Spacing between } \\
\text { stimulation sessions }\end{array}$ & $\begin{array}{r}\text { Non-normal } \\
\text { distribution }\end{array}$ & $\begin{array}{l}\text { Mann-Whitney (between } \\
\text { groups; PPC group: } \\
\text { participants receiving } \\
3 \text { vs } 4 \text { d of } \\
\text { stimulation) }\end{array}$ & & $\mathrm{R}$ & $W=36$ & $p=0.327$ & $\begin{array}{l}\text { Mean }=0.1092, \\
95 \% \mathrm{Cl}[-0.0743, \\
0.2110]\end{array}$ \\
\hline$b$ & & Current & $\begin{array}{l}\text { Average motion } \\
\text { displacement }\end{array}$ & $\begin{array}{l}\text { Non-normal } \\
\text { distribution }\end{array}$ & $\begin{array}{l}\text { Wilcox rank-sum (all } \\
\text { subjects; post vs pre) }\end{array}$ & & $\mathrm{R}$ & $V=167$ & $p=0.194$ & $\begin{array}{l}\text { Mean }=0.007495 \% \\
\quad \mathrm{Cl}[-0.0032, \\
0.0204]\end{array}$ \\
\hline c & & Current & $\begin{array}{l}\text { Average motion } \\
\text { displacement }\end{array}$ & $\begin{array}{l}\text { Non-normal } \\
\text { distribution }\end{array}$ & $\begin{array}{l}\text { Mann-Whitney (parietal } \\
\text { vs vertex) }\end{array}$ & & $\mathrm{R}$ & $W=199.5$ & $p=0.350$ & $\begin{array}{l}\text { Mean }=-0.0099 \\
\quad 95 \% \mathrm{Cl}[-0.0225, \\
0.0096]\end{array}$ \\
\hline$d$ & & Current & Number of censored trials & $\begin{array}{l}\text { Non-normal } \\
\text { distribution }\end{array}$ & $\begin{array}{l}\text { Wilcox rank-sum (all } \\
\text { subjects; post vs pre) }\end{array}$ & & $\mathrm{R}$ & $V=118.5$ & $p=0.155$ & $\begin{array}{l}\text { Mean }=2.500095 \% \\
\quad \mathrm{Cl}[-0.9999, \\
6.5000]\end{array}$ \\
\hline e & & Current & Number of censored trials & $\begin{array}{l}\text { Non-normal } \\
\text { distribution }\end{array}$ & $\begin{array}{l}\text { Mann-Whitney (parietal } \\
\text { vs vertex) }\end{array}$ & & $\mathrm{R}$ & $W=218.5$ & $p=0.604$ & $\begin{array}{l}\text { Mean }=-2.1121 \\
\quad 95 \% \mathrm{Cl}[-3.0000, \\
0.00004]\end{array}$ \\
\hline$f$ & 2 & Current & $\begin{array}{l}\text { Whole-brain FC analysis, } \\
\text { retrosplenial cortex }\end{array}$ & $\begin{array}{l}\text { Non-normal } \\
\text { distribution }\end{array}$ & $\begin{array}{l}\text { Wilcox rank-sum (within- } \\
\text { groups; PPC group, } \\
\text { post hoc test, post vs } \\
\text { pre active } \\
\text { stimulation) }\end{array}$ & Bonferroni & $\mathrm{R}$ & $V=7$ & $p=1.16 \times 10^{-3}$ & $\begin{array}{l}\text { Mean }=0.1697 \\
\quad 95 \% \mathrm{Cl}[0.0654 \\
0.2590]\end{array}$ \\
\hline g & 2 & Current & $\begin{array}{l}\text { Whole-brain FC analysis, } \\
\text { fusiform gyrus }\end{array}$ & $\begin{array}{l}\text { Non-normal } \\
\text { distribution }\end{array}$ & $\begin{array}{l}\text { Wilcox rank-sum (within- } \\
\text { groups; PPC group, } \\
\text { post hoc test, post vs } \\
\text { pre active } \\
\text { stimulation) }\end{array}$ & Bonferroni & $\mathrm{R}$ & $V=4$ & $p=4.27 \times 10^{-4}$ & $\begin{array}{l}\text { Mean }=0.1475, \\
95 \% \mathrm{Cl}[0.0951, \\
0.2132]\end{array}$ \\
\hline $\mathrm{h}$ & 2 & Current & $\begin{array}{l}\text { Whole-brain FC analysis, } \\
\text { lateral PC }\end{array}$ & $\begin{array}{l}\text { Non-normal } \\
\text { distribution }\end{array}$ & $\begin{array}{l}\text { Wilcox rank-sum (within- } \\
\text { groups; PPC group, } \\
\text { post hoc test, post vs } \\
\text { pre active } \\
\text { stimulation) }\end{array}$ & Bonferroni & $\mathrm{R}$ & $V=1$ & $p=1.22 \times 10^{-4}$ & $\begin{array}{l}\text { Mean }=0.1331 \\
95 \% \mathrm{Cl}[0.0777, \\
0.2034]\end{array}$ \\
\hline i & 2 & Current & $\begin{array}{l}\text { Whole-brain FC analysis, } \\
\text { superior PC }\end{array}$ & $\begin{array}{l}\text { Non-normal } \\
\text { distribution }\end{array}$ & $\begin{array}{l}\text { Wilcox rank-sum (within- } \\
\text { groups; PPC group, } \\
\text { post hoc test, post vs } \\
\text { pre active } \\
\text { stimulation) }\end{array}$ & Bonferroni & $\mathrm{R}$ & $V=2$ & $p=1.83 \times 10^{-4}$ & $\begin{array}{l}\text { Mean }=0.1682, \\
95 \% \mathrm{Cl}[0.0815, \\
0.2294]\end{array}$ \\
\hline j & $3 A$ & Current & $\begin{array}{l}\text { Hippocampal-LPOC FC } \\
\text { changes (a priori) }\end{array}$ & $\begin{array}{l}\text { Non-normal } \\
\text { distribution }\end{array}$ & $\begin{array}{l}\text { Wilcox rank-sum (within- } \\
\text { groups; PPC group, } \\
\text { post vs pre active } \\
\text { stimulation) }\end{array}$ & & $\mathrm{R}$ & $V=95$ & $p=0.048$ & $\begin{array}{l}\text { Mean }=0.0867, \\
95 \% \mathrm{Cl}[0.0013, \\
0.2053]\end{array}$ \\
\hline k & $3 A$ & Current & $\begin{array}{l}\text { Hippocampal-LPOC FC } \\
\text { changes (a priori) }\end{array}$ & $\begin{array}{l}\text { Non-normal } \\
\text { distribution }\end{array}$ & $\begin{array}{l}\text { Mann-Whitney (between } \\
\text { groups; PPC group } \\
\text { vs vertex group) }\end{array}$ & & $\mathrm{R}$ & $W=93$ & $p=0.034$ & $\begin{array}{l}\text { Mean }=0.1367, \\
95 \% \mathrm{Cl}[0.0195, \\
0.3257]\end{array}$ \\
\hline I & 4 & Current & $\begin{array}{l}\text { Hippocampal-LPOC FC } \\
\text { changes }\end{array}$ & $\begin{array}{l}\text { Non-normal } \\
\text { distribution }\end{array}$ & $\begin{array}{l}\text { Permutation test } \\
\text { (between groups; } \\
\text { PPC group vs vertex } \\
\text { group) }\end{array}$ & & $\mathrm{R}$ & $\begin{array}{l}\text { Observed mean } \\
\quad \text { difference }= \\
0.1795\end{array}$ & & $\begin{array}{r}95 \% \text { of distribution } \\
{[0.1098,0.2536]}\end{array}$ \\
\hline $\mathrm{m}$ & $3 A$ & Current & $\begin{array}{l}\text { Hippocampal-LPOC FC } \\
\text { changes (a priori) }\end{array}$ & $\begin{array}{l}\text { Non-normal } \\
\text { distribution }\end{array}$ & $\begin{array}{l}\text { Wilcox rank-sum (within } \\
\text { groups; vertex group, } \\
\text { post vs pre active } \\
\text { stimulation) }\end{array}$ & & $\mathrm{R}$ & $V=7$ & $p=0.148$ & $\begin{array}{l}\text { Mean }=-0.0477, \\
95 \% \mathrm{Cl}[-0.0554, \\
0.2357]\end{array}$ \\
\hline $\mathrm{n}$ & $3 A$ & Current & $\begin{array}{l}\text { DLPFC-LPOC FC changes } \\
\quad \text { (a priori) }\end{array}$ & $\begin{array}{l}\text { Non-normal } \\
\text { distribution }\end{array}$ & $\begin{array}{l}\text { Wilcox rank-sum (within } \\
\text { groups; PPC group, } \\
\text { post vs pre active } \\
\text { stimulation) }\end{array}$ & & $\mathrm{R}$ & $V=81$ & $p=0.252$ & $\begin{array}{l}\text { Mean }=0.0444, \\
95 \% \mathrm{Cl}[-0.0344, \\
0.1270]\end{array}$ \\
\hline o & $3 A$ & Current & $\begin{array}{l}\text { DLPFC and Hippocampal- } \\
\text { LPOC changes (a } \\
\text { priori) }\end{array}$ & $\begin{array}{l}\text { Non-normal } \\
\text { distribution }\end{array}$ & $\begin{array}{l}\text { Wilcox rank-sum (within } \\
\text { groups; PPC group, } \\
\text { DLPFC-LPOC vs } \\
\text { hippocampal-LPOC } \\
\text { FC) }\end{array}$ & & $\mathrm{R}$ & $V=75$ & $p=0.421$ & $\begin{array}{l}\text { Mean }=0.0344, \\
95 \% \mathrm{Cl}[-0.0636, \\
0.1593]\end{array}$ \\
\hline $\mathrm{p}$ & & Current & $\begin{array}{l}\text { GC-LPOC changes (a } \\
\text { priori) }\end{array}$ & $\begin{array}{l}\text { Non-normal } \\
\text { distribution }\end{array}$ & $\begin{array}{l}\text { Wilcox rank-sum (within } \\
\text { groups; PPC group, } \\
\text { post vs pre active } \\
\text { stimulation) }\end{array}$ & & $\mathrm{R}$ & $V=94$ & $p=0.055$ & $\begin{array}{l}\text { Mean }=0.0179, \\
95 \% \mathrm{Cl}[-0.0006, \\
0.0434]\end{array}$ \\
\hline$q$ & & Current & $\begin{array}{l}\text { GC and Hippocampal-FC } \\
\text { changes (a priori) }\end{array}$ & $\begin{array}{l}\text { Non-normal } \\
\text { distribution }\end{array}$ & $\begin{array}{l}\text { Wilcox rank-sum (within } \\
\text { groups; PPC group, } \\
\text { post vs pre active } \\
\text { stimulation) } \\
\text { (Continued) }\end{array}$ & & $\mathrm{R}$ & $V=92$ & $p=0.073$ & $\begin{array}{l}\text { Mean }=0.0641, \\
95 \% \mathrm{Cl}[-0.0066, \\
0.1547]\end{array}$ \\
\hline
\end{tabular}


Table 1. Continued

\begin{tabular}{|c|c|c|c|c|c|c|c|c|c|c|}
\hline Manuscript & Figure & Sample & Data type & Data structure & Type of test & $\begin{array}{c}\text { Multiple } \\
\text { comparison } \\
\text { correction }\end{array}$ & Program & Statistics & $p$ values & Confidence intervals \\
\hline r & & Current & $\begin{array}{l}\text { DLPFC and hippocampal } \\
\text { target changes (control } \\
\text { analysis) }\end{array}$ & $\begin{array}{l}\text { Normally } \\
\text { distributed }\end{array}$ & $\begin{array}{l}\text { Paired } t \text { test } \\
\text { (within-groups; PPC } \\
\text { group, post vs per } \\
\text { active stimulation) }\end{array}$ & & $\mathrm{R}$ & $t_{(14)}=0.949$ & $p=0.359$ & $\begin{array}{l}\text { Mean }=0.04895 \% \\
\quad \mathrm{Cl}[-0.061,0.157]\end{array}$ \\
\hline S & & Current & $\begin{array}{l}\text { DLPFC and stimulus } \\
\text { location changes } \\
\text { (control analysis) }\end{array}$ & $\begin{array}{l}\text { Non-normal } \\
\text { distribution }\end{array}$ & $\begin{array}{l}\text { Wilcox rank-sum (within- } \\
\text { groups; PPC group, } \\
\text { post vs per active } \\
\text { stimulation) }\end{array}$ & & $\mathrm{R}$ & $V=68$ & $p=0.679$ & $\begin{array}{l}\text { Mean }=0.02695 \% \\
\quad \mathrm{Cl}[-0.103,0.121]\end{array}$ \\
\hline $\mathrm{t}$ & & Current & Changes in PPC GC & $\begin{array}{l}\text { Non-normal } \\
\text { distribution }\end{array}$ & $\begin{array}{l}\text { Wilcox rank-sum (within- } \\
\text { groups; PPC group, } \\
\text { post vs per active } \\
\text { stimulation) }\end{array}$ & & $\mathrm{R}$ & $V=92$ & $p=0.073$ & $\begin{array}{l}\text { Mean }=0.02295 \% \\
\quad \mathrm{Cl}[-0.005,0.050]\end{array}$ \\
\hline $\mathrm{u}$ & $3 B$ & Current & $\begin{array}{c}\text { Hippocampal FC changes } \\
\text { within Yeo Networks }\end{array}$ & $\begin{array}{l}\text { Normally } \\
\text { distributed }\end{array}$ & $\begin{array}{l}\text { Paired } t \text { test (within } \\
\text { groups; PPC group, } \\
\text { post vs pre active } \\
\text { stimulation) }\end{array}$ & & $\mathrm{R}$ & $t_{(16)}=10.96$ & $p=7.6 \times 10^{-9}$ & $\begin{array}{l}\text { Mean }=0.0900 \\
\quad 95 \% \mathrm{Cl}[0.0725 \\
0.1073]\end{array}$ \\
\hline v & $3 B$ & $\begin{array}{l}\text { Wang et al. } \\
\qquad(2014)\end{array}$ & $\begin{array}{l}\text { Hippocampal FC changes } \\
\text { within Yeo networks }\end{array}$ & $\begin{array}{l}\text { Normally } \\
\text { distributed }\end{array}$ & $\begin{array}{l}\text { Paired } t \text { test (within } \\
\text { groups; PPC group, } \\
\text { post vs pre active } \\
\text { stimulation) }\end{array}$ & & $\mathrm{R}$ & $t_{(16)}=11.27$ & $p=5.10 \times 10^{-9}$ & $\begin{array}{l}\text { Mean }=0.0169 \\
95 \% \mathrm{Cl}[0.0138 \\
0.0201]\end{array}$ \\
\hline w & $3 B$ & Both samples & $\begin{array}{c}\text { Hippocampal FC changes } \\
\text { within Yeo networks }\end{array}$ & $\begin{array}{l}\text { Normally } \\
\text { distributed }\end{array}$ & $\begin{array}{l}\text { Paired } t \text { test (between } \\
\text { groups; current vs } \\
\text { Wang, active } \\
\text { stimulation) }\end{array}$ & & $\mathrm{R}$ & $t_{(32)}=8.75$ & $\begin{array}{c}p=5.42 \times \\
10^{-10}\end{array}$ & $\begin{array}{l}95 \% \mathrm{Cl}[0.0560 \\
0.0900]\end{array}$ \\
\hline$x$ & 6 & Both samples & $\begin{array}{l}\text { Hippocampal FC changes } \\
\text { within Yeo networks }\end{array}$ & $\begin{array}{r}\text { Non-Normally } \\
\text { distributed }\end{array}$ & $\begin{array}{l}\text { Spearman correlation } \\
\text { across samples } \\
\text { (current and Wang) }\end{array}$ & & $\mathrm{R}$ & $r=0.51$ & $p=0.037$ & $\begin{array}{l}95 \% \mathrm{Cl}[0.0389, \\
0.7956]\end{array}$ \\
\hline y & & Both samples & $\begin{array}{l}\text { GC changes within } \mathrm{Yeo} \\
\text { networks }\end{array}$ & $\begin{array}{r}\text { Non-Normally } \\
\text { distributed }\end{array}$ & $\begin{array}{l}\text { Spearman correlation } \\
\text { across samples } \\
\text { (current and Wang) }\end{array}$ & & $\mathrm{R}$ & $r=0.16$ & $p=0.536$ & $\begin{array}{l}95 \% \mathrm{Cl}[-0.3419 \\
0.5989]\end{array}$ \\
\hline$z$ & 8 & Current & $\begin{array}{l}\text { Hippocampal FC changes } \\
\text { in significant regions }(p \\
\quad<0.01)\end{array}$ & $\begin{array}{l}\text { Non-normal } \\
\text { distribution }\end{array}$ & $\begin{array}{l}\text { Spearman correlation } \\
\text { (within groups; } \\
\text { baseline hippocampal } \\
\text { FC and hippocampal- } \\
\text { FC changes) }\end{array}$ & & $\mathrm{R}$ & $r=0.39$ & $p=1.0 \times 10^{-4}$ & $\begin{array}{c}95 \% \mathrm{Cl}[0.2002 \\
0.5453]\end{array}$ \\
\hline aa & & Current & $\begin{array}{l}\text { Hippocampal FC changes } \\
\text { in significant regions ( } p \\
<0.01 \text { ), outlier } \\
\text { removed }\end{array}$ & $\begin{array}{l}\text { Normally } \\
\text { distributed }\end{array}$ & $\begin{array}{l}\text { Pearson correlation } \\
\text { (within groups; } \\
\text { baseline hippocampal } \\
\text { FC and hippocampal- } \\
\text { FC changes) }\end{array}$ & & $\mathrm{R}$ & $r_{(92)}=0.47$ & $p=1.14 \times 10^{-6}$ & $\begin{array}{l}95 \% \mathrm{Cl}[0.2955 \\
0.6141]\end{array}$ \\
\hline $\mathrm{bb}$ & 8 & Current & $\begin{array}{l}\text { GC changes in significant } \\
\text { regions }(p<0.01)\end{array}$ & $\begin{array}{l}\text { Non-normal } \\
\text { distribution }\end{array}$ & $\begin{array}{l}\text { Spearman correlation } \\
\text { (within groups; } \\
\text { baseline GC and GC } \\
\text { changes) }\end{array}$ & & $\mathrm{R}$ & $r=-0.08$ & $p=0.39$ & $\begin{array}{c}95 \% \mathrm{Cl}[-0.2593 \\
0.1046]\end{array}$ \\
\hline
\end{tabular}

Each analysis includes a letter indicator ("manuscript" column) linking the test in the table to the analysis in the text. The link to the corresponding figure, if any, and the sample used for the test are indicated in the "figure," and "sample," columns, respectively. The "current" sample includes tests using data from the current work, and the previous study is indicated as Wang et al. (2014), the dependent variables for each test are listed as "data type," and the "data structure" column indicates whether the data are normally distributed. The type of test, contrast, and the groups used for the analysis are listed in the "type of test" column. The multiple correction method is listed under "multiple comparisons correction." the program used to perform the analysis is included under "program." The critical value and degrees of freedom are listed for each test under "statistics." Finally, the $p$ value and confidence intervals are listed in the final two columns. DLPFC, dorsolateral prefrontal cortex; GC, global connectedness; LPOC, left precuneus and medial occipital cortex.

(Table 1, p, $V=94, p=0.055,95 \% \mathrm{Cl}[-0.0006$ 0.04139]). However, there was a trend-level difference between the GC and hippocampal FC changes in the LPOC region (Table 1, q, $V=92, p=0.073,95 \% \mathrm{Cl}$ $[-0.0066,0.1547])$. We conducted additional control analyses to determine whether stimulation caused significant increases in FC between the DLPFC and the hippocampus, but it did not (Table 1, $r, t_{(14)}=0.949, p=0.359,95 \%$ $\mathrm{Cl}[-0.061,0.157])$, nor were there changes in FC between the DLPFC and the stimulus location in the PPC (Table 1, s, $V=68, p=0.679,95 \% \mathrm{Cl}[-0.103,0.121])$, nor did PPC-GC increase (Table 1, t, $V=92, p=0.073,95 \% \mathrm{Cl}$ $[-0.005,0.050])$.

In the current sample, there was an increase in hippocampal FC with the 17 networks identified by Yeo et al.
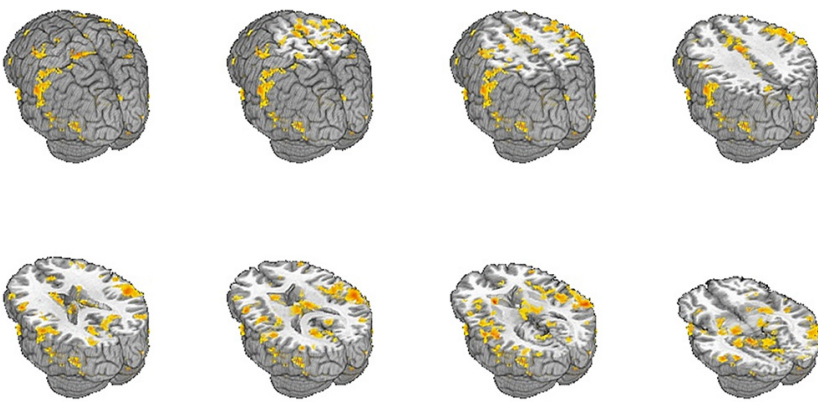

Figure 2. Regions showing significant change in hippocampal FC following PPC rTMS from the current study (FDR corrected, $q=0.05)$. 
A

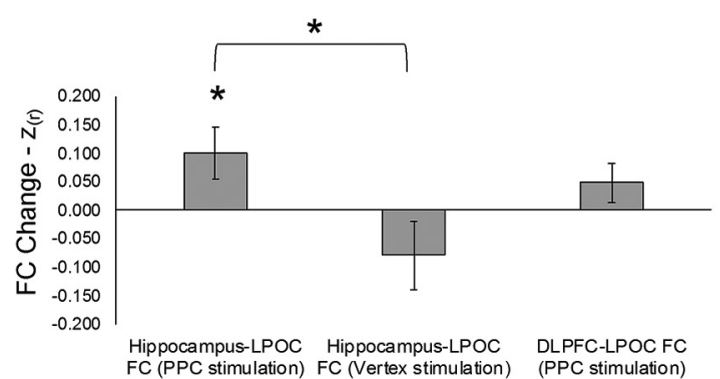

B

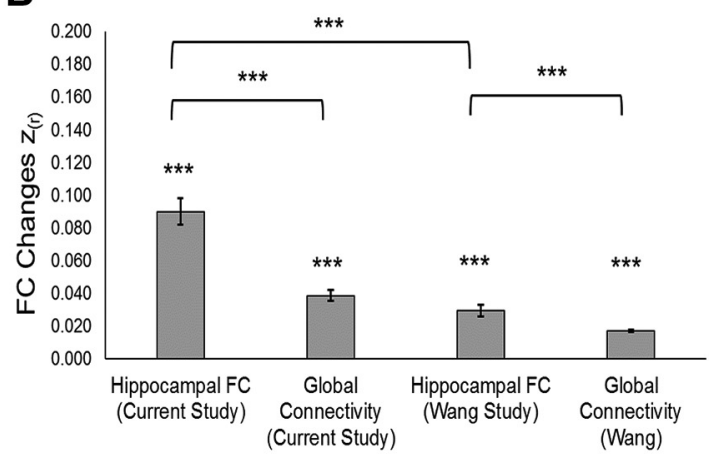

Figure 3. A, Average change in hippocampal-LPOC FC for subjects receiving PPC stimulation (left bar) and vertex stimulation (middle bar). Average DLPFC-LPOC FC changes for subjects receiving PPC stimulation is represented by the right bar. $\boldsymbol{B}$, Mean changes in hippocampal FC within 17 segregated networks from Yeo et al. (2011) after PPC rTMS in this study and Wang et al., and change in GC within networks from both studies. Error bars represent the standard error of the mean; $* p<0.05, * * * p<0.0001$.

(2011), which was significantly stronger than the GC changes in these networks (Table 1, u, $t_{(16)}=10.96,7.6 \times$ $\left.10^{-9}, 95 \% \mathrm{Cl}[0.0725,0.1073]\right)$. We found the same effect in the data from Wang et al. (Table 1, v, $t_{(16)}=11.27, p=$ $5.10 \times 10^{-9}, 95 \% \mathrm{Cl}[0.0138,0.0201]$; Fig. 3B). Comparing the hippocampal FC changes between studies, we found that they were larger in the current study, despite using fewer stimulation sessions (Table $1, \mathrm{w}, t_{(32)}=8.75$, $\left.p=5.42 \times 10^{-10}, 95 \% \mathrm{Cl}[0.0560,0.09]\right)$, although GC changes were also larger in the current results than in the Wang et al. data. This suggests overall differences in the magnitude of FC changes across experiments, which could reflect factors such as different scan variables be- tween studies. After PPC stimulation in both studies, increases in hippocampal FC were maximal in networks that included the cuneus and retrosplenial, somatosensory, and superior temporal, areas (Fig. 5).

In our test for whether the whole-brain topographic patterns of rTMS-induced hippocampal FC were similar between studies, we found that FC changes were correlated between studies (Table 1, x, $r=0.51, n=17, p=$ $0.037,95 \% \mathrm{Cl}[0.0389,0.7956]$; Fig. 6). There was no significant correlation between the GC changes in the current study with the hippocampal FC changes of Wang et al. (Table 1, y, $r=0.16, n=17, p=0.536,95 \% \mathrm{Cl}$ $[-0.3419,0.5989])$. These results indicate that the magni-

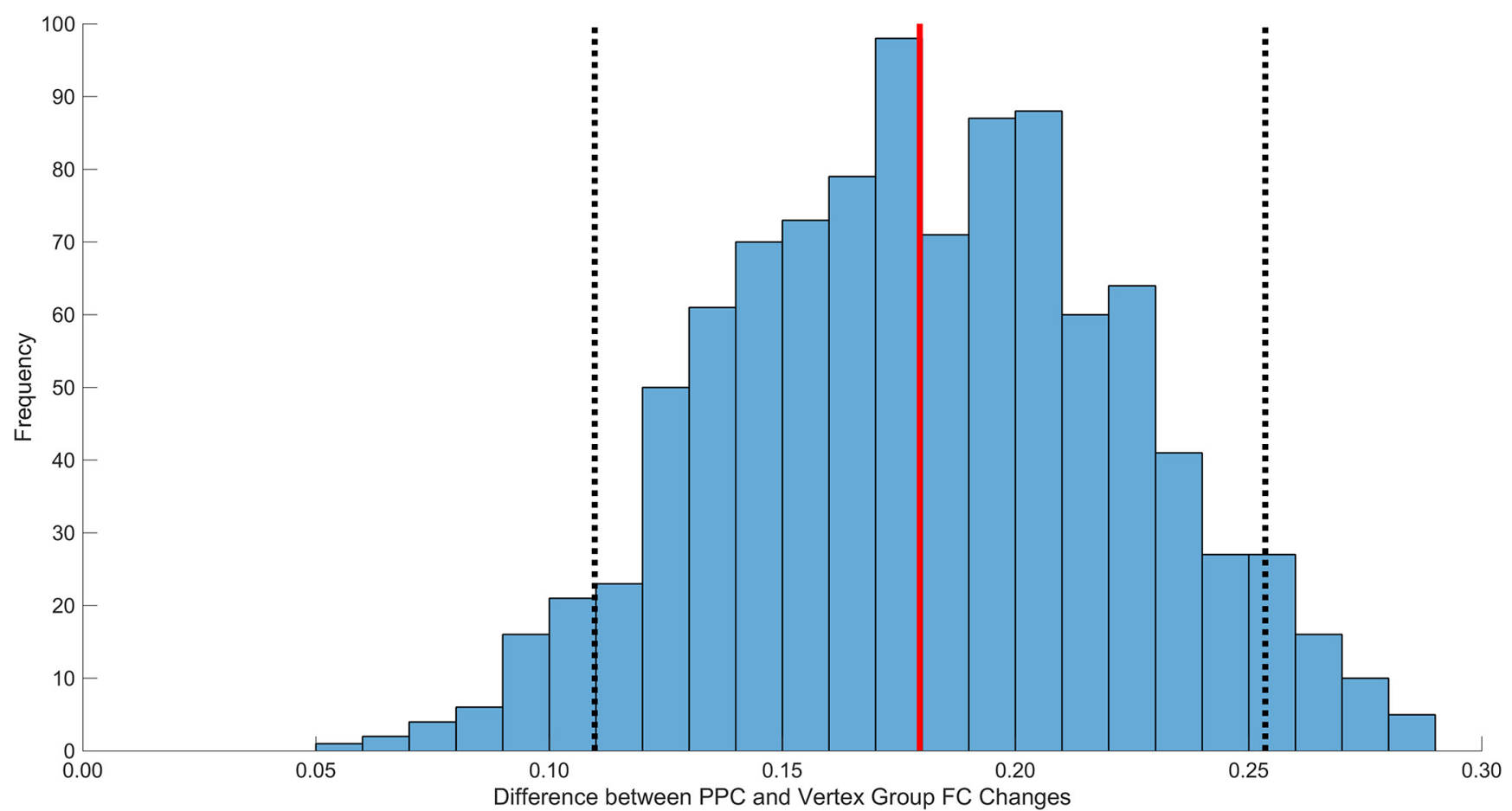

Figure 4. Histogram representing the result of 1000 group mean differences using eight subjects from each group, where the eight PPC subjects are randomly sampled each time. The black dotted lines represent the upper (0.2536) and lower (0.1098) limit of $95 \%$ of the distribution. The observed mean difference between the PPC and vertex group is shown by the red line (0.1795). 


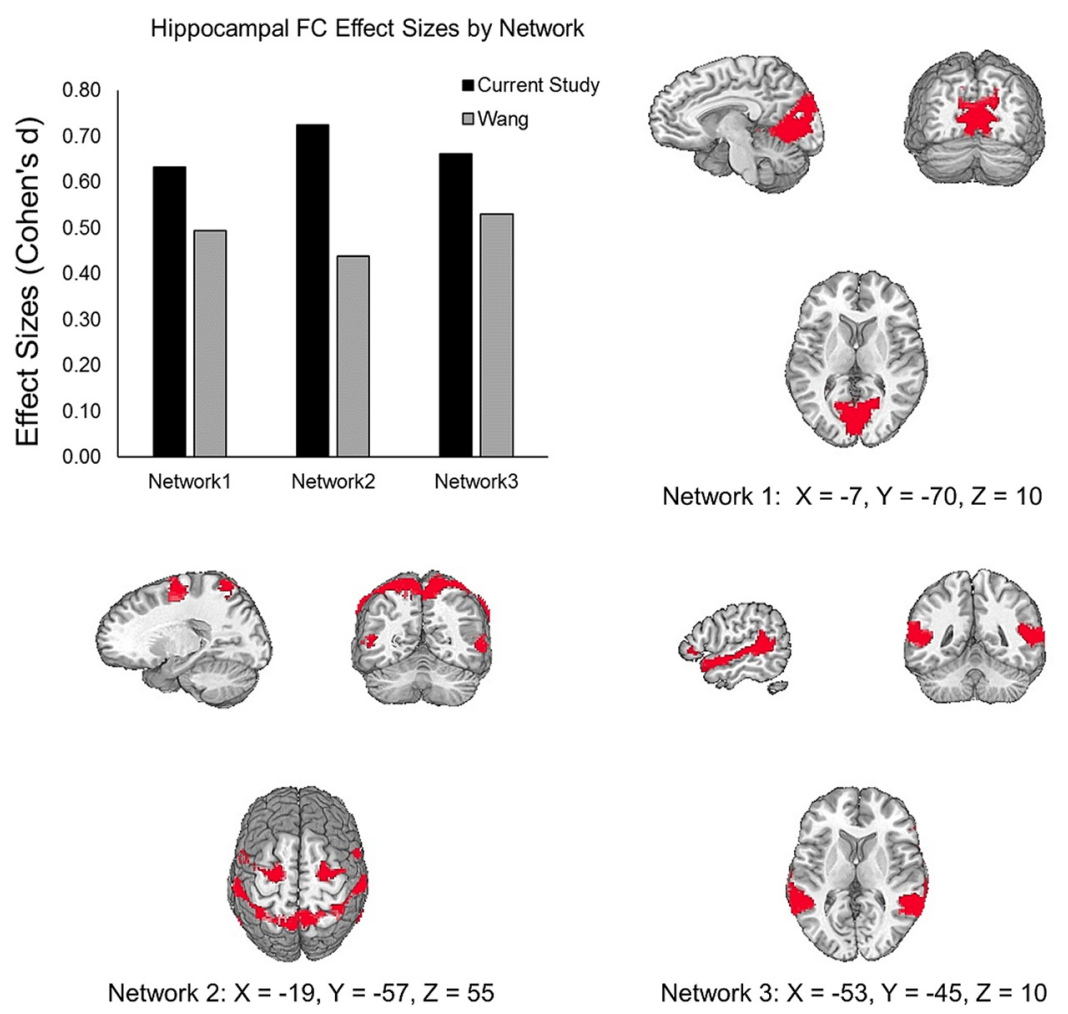

Figure 5. Effect size of increases in hippocampal FC within three representative networks from Yeo et al. (2011) after PPC rTMS in this study and Wang et al. Network 1 includes cuneus and retrosplenial cortex. Network 2 includes somatosensory areas. Network 3 includes superior temporal areas.

tude of hippocampal FC changes across networks was similar between studies and that their topographic distribution was reproducible.

Finally, we reproduced the finding that, among areas showing significant increases in hippocampal FC after PPC rTMS, prestimulation hippocampal FC predicted the magnitude of the increase (Fig. 7A). This was confirmed by the relationship between the baseline and mean change in hippocampal FC across areas (Table 1, z, $r=$ $0.39, n=95, p=1.0 \times 10^{-4}, 95 \% \mathrm{Cl}[0.2002,0.5453]$; Fig. $8 A$ ). Removing the single outlier did not change the significance of the correlation (Table 1, aa, $r_{(92)}=0.47, p$ $\left.=1.14 \times 10^{-6}, 95 \% \mathrm{Cl}[0.2955,0.6141]\right)$. We did not observe the same pattern of results when performing the same analyses using GC as the dependent variable (Table 1, bb, $r=-0.08, n=115, p=0.39,95 \% \mathrm{Cl}$ $[-0.2593,0.1046]$; Figs. $7 B, 8 B)$. These findings indicate a specific effect of PPC rTMS on the hippocampus and rule out non-specific enhancement of FC across the brain. Re-sorting the matrices in Figure 7 revealed no regional differences in the change in GC (Fig. 7B), but did show that, among regions connected to the hippocampus at

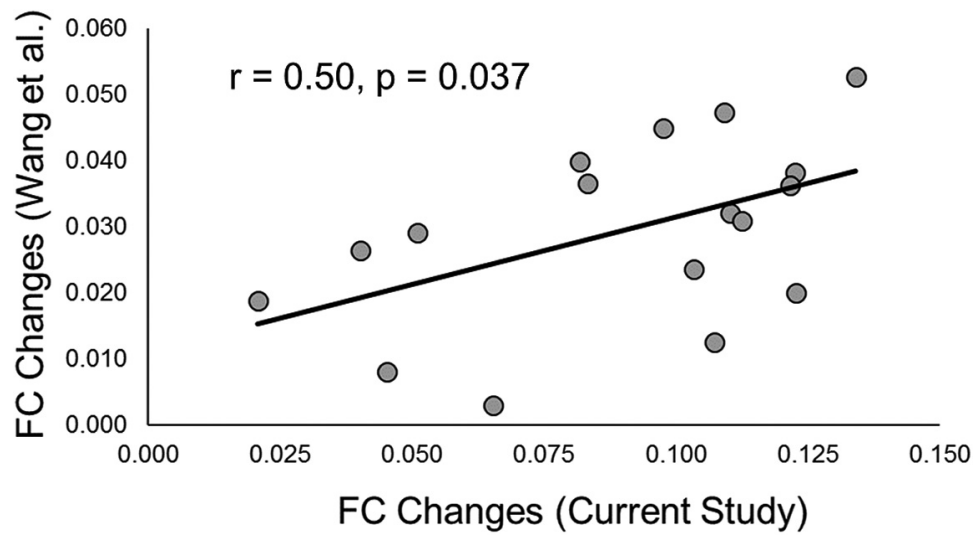

Figure 6. Scatterplot of PPC rTMS-induced hippocampal FC $\left[z_{(r)}\right]$ changes across networks from Yeo et al. (2011). Each dot represents the rTMS-induced hippocampal FC change from the current study ( $x$-axis) and Wang et al. ( $y$-axis) within one of the 17 networks from Yeo et al. (2011). The black line represents the regression line across individual data points. 


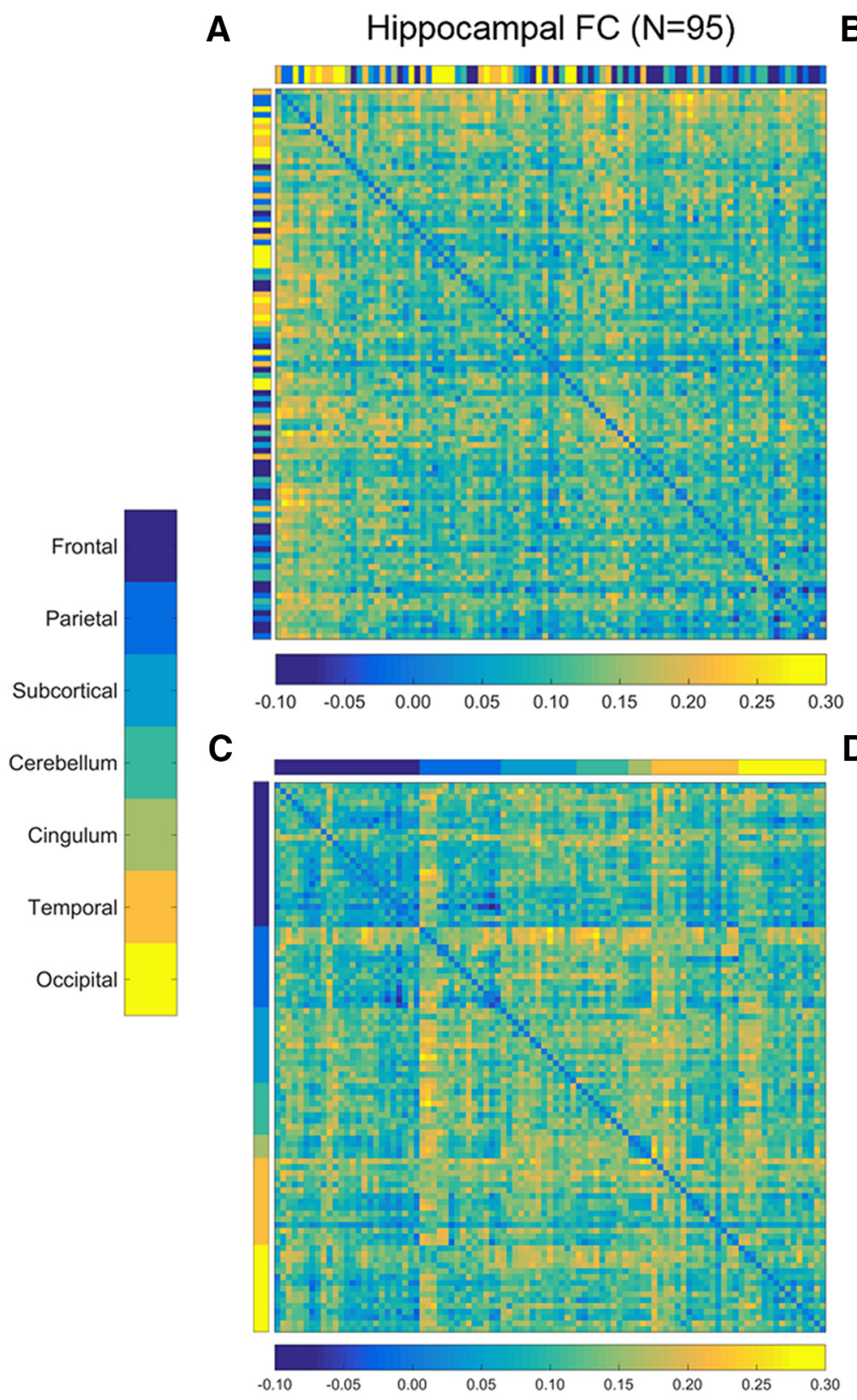

$\Delta$ fMRI connectivity $z(r)$
B Global Connectedness $(\mathrm{N}=117)$

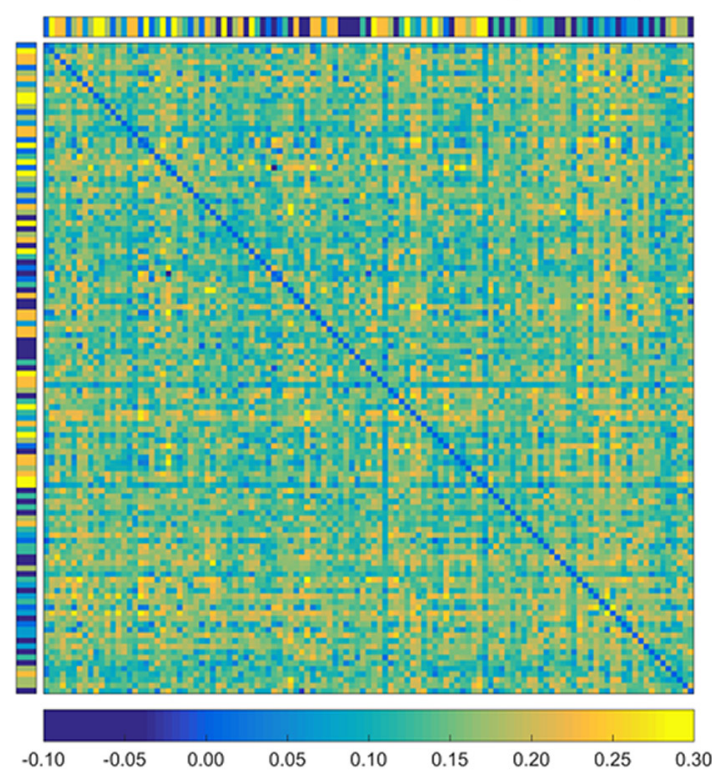

D

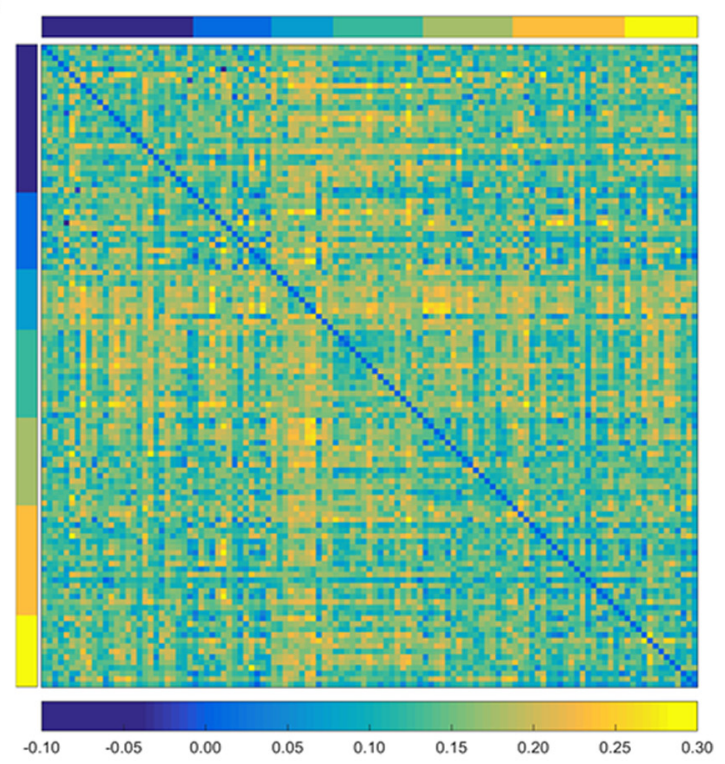

$\triangle \mathrm{fMRI}$ connectivity $z(r)$

Figure 7. Correlation matrices of regions demonstrating significant $(p<0.01)$ changes in hippocampal $(\boldsymbol{A})$ and global $(\boldsymbol{B})$ FC. Matrices are sorted by baseline FC with the highest values represented at the top of the matrices on the $y$-axis and to the left on the $x$-axis. Color bars aligned with each axis represent AAL-defined regions. $\boldsymbol{C}, \boldsymbol{D}$, Identical to $\boldsymbol{A}, \boldsymbol{B}$ but are sorted by region.

baseline, frontal regions showed qualitatively less change than more posterior regions, such as the PPC, similar to the results of Wang et al. (2014) and consistent with the interpretation that areas with higher baseline FC with the hippocampus change most with PPC rTMS.

\section{Discussion}

We independently reproduced the highly specific increase in hippocampal FC, reported by Wang et al. (2014), resulting from high-frequency rTMS of PPC, using a partial replication of their technique and adding additional new controls. We applied a whole-brain analysis as well as a hypothesis-based approach, predicated on the anatomic distribution of changes reported by Wang et al. (2014). We also looked for changes in hippocampal FC within 17 additional segregated brain networks (Yeo et al., 2011). The whole-brain comparison to Wang et al. (2014) revealed that PPC rTMS caused significant hippocampal FC changes in all of the regions reported by Wang et al., as well as several others. The hypothesis-based approach revealed significant increases in hippocampal FC with the LPOC, a region derived from our re-analysis of the Wang et al. (2014) data. These changes were specific to FC with 
A

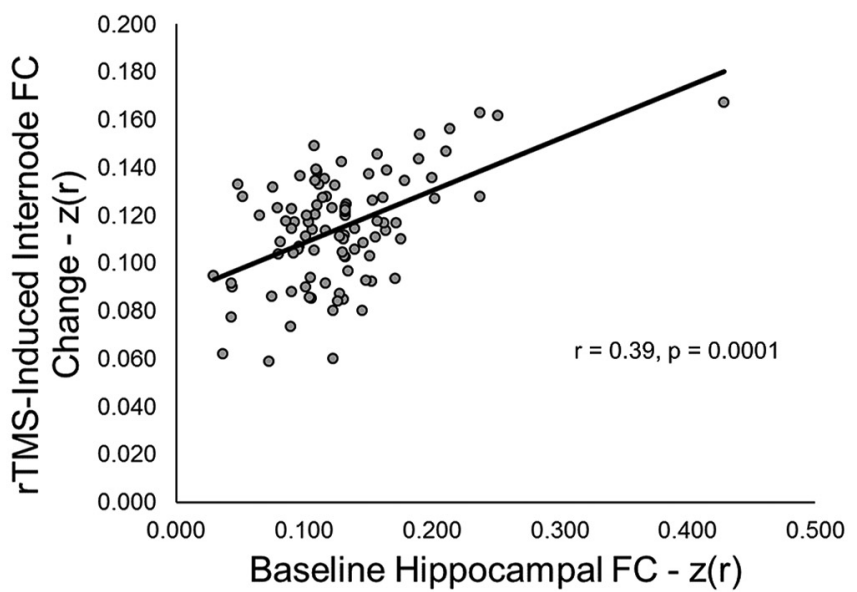

B

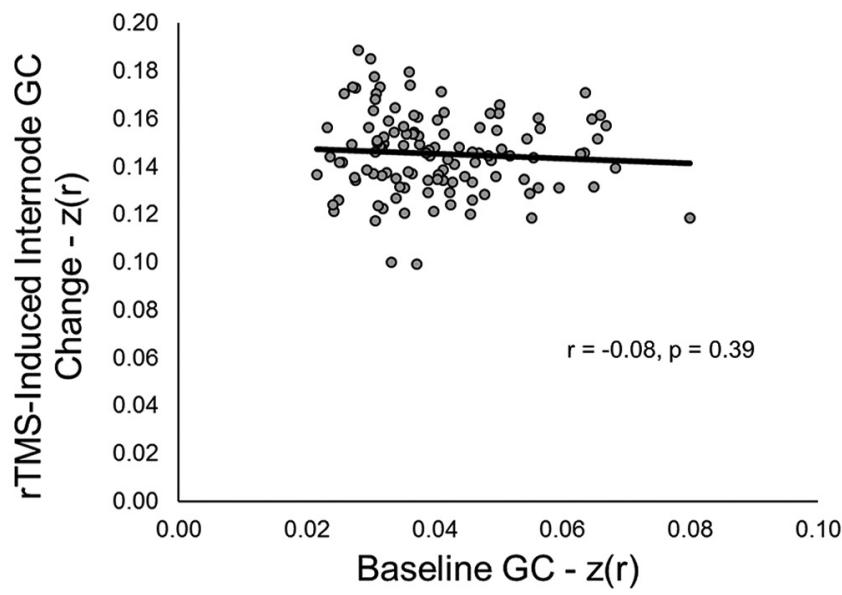

Figure 8. $\boldsymbol{A}$, Scatterplot of baseline hippocampal FC for regions demonstrating significant $(p<0.01)$ changes in hippocampal FC and average rTMS-induced FC change in those regions. $\boldsymbol{B}$, Scatterplot of baseline GC for regions demonstrating significant $(p<0.01)$ changes in GC and average rTMS-induced internode GC change in those regions.

the hippocampus: PPC rTMS did not significantly increase FC between the DLPFC, an area active in many cognitive processes including learning, and the LPOC. We also ruled out the possibility that the findings reflected a general increase in brain connectivity: Hippocampal FC was significantly greater than GC across all networks examined in both the present and the Wang et al. data. Although our vertex control sample was small, we found no significant FC changes in this group and hippocampus-LPOC FC was significantly greater for the PPC rTMS group than the vertex group.

As in the data of Wang et al. (2014), baseline hippocampal FC predicted PPC rTMS-induced FC changes and we demonstrated the specificity of this relationship by showing that baseline GC did not predict GC increases after rTMS. Finally, the spatial pattern of rTMS-induced FC change was similar and correlated between studies. Taken together, this is strong evidence that the effect of $20-\mathrm{Hz}$ rTMS on the PPC on hippocampal FC is robust, reproducible, and highly specific in anatomic terms.

Notably, we were able to reproduce, and possibly to exceed, the results of Wang et al. (2014) with fewer stimulation sessions. Multiple consecutive rTMS sessions are burdensome to subjects and investigators alike and reducing the requirement increases the attractiveness of the PPC rTMS paradigm.

Our vertex rTMS group showed decreased hippocampal FC with almost every network, including the LPOC. This unexplained time-related drift could be due to a physiologic effect and might represent a potential confound. However, as noted above, others (Jung et al., 2016) have found no evidence of FC changes from vertex rTMS. Additionally, the average change in hippocampal FC across the networks from Yeo et al. (2011) in the Wang et al. (2014) sham data did not differ significantly from zero.

There were several procedural differences between the current work and that of Wang et al. (2014), the most obvious of which was the absence of behavioral testing.
Therefore, we do not know whether the changes in hippocampal FC were associated with an improvement in declarative memory. Additionally, there were differences in how we preprocessed our resting-state data. We did not bandpass filter our data and, unlike Wang et al. (2014), we included spatial smoothing to reduce the influence of spatial noise and increase signal-to-noise ratio (SNR).

Another difference between studies was our use of a vertex stimulation control. Wang et al. (2014) used subthreshold stimulation (10\% of RMT) of the PPC as their within-subjects control, which may have caused weak local brain effects without reproducing the somatosensory effect of full-intensity rTMS. They also used fullintensity stimulation of the motor cortex in an independent group as a secondary control, and this was all but certain to produce widespread changes in FC. We chose activeintensity stimulation at the vertex as our control because others (Jung et al., 2016) found no effect on FC from stimulation there. This site lies over the sagittal sinus and the interhemispheric fissure, where the cortex is relatively distant from the coil and the nearest regions are out of the plane of the stimulating current. Neither in this, nor the study of Wang et al. (2014), did control stimulation produce any measurable increase in hippocampal FC.

Finally, for reasons described above, we used three and, in some cases, $4 \mathrm{~d}$ of rTMS, while Wang et al. (2014) used five. This study contains no basis for a quantitative comparison of the strength or duration of the connectivity or behavioral changes produced by various treatment durations, but 3-4 d appears adequate to produce FC changes similar to those of Wang et al. (2014) at a 24-h delay. These procedural differences do not allow us to claim a strict replication of the paradigm, but they do not detract from the substantial reproduction of the result and could not have caused it by themselves.

Both we and Wang et al. (2014) were able to produce dramatic increases in hippocampal network FC with a few sessions of PPC rTMS, making this one of the strongest and most reliable effects in noninvasive neuromodulation. 
The differences in the treatment paradigms and image processing procedures decrease the likelihood that both studies arrived at a similar result due to an artifact or systematic noise. Others (van der Werf et al., 2010; Vercammen et al., 2010; Gratton et al., 2013; Rahnev et al., 2013; Steel et al., 2016; Rastogi et al., 2017) have also used FC to study how rTMS affects brain function at the network level. FC in the default mode network appears to be particularly sensitive to modulation with rTMS (Eldaief et al., 2011; Halko et al., 2014; Wang et al., 2014) and can be modulated by stimulating the PPC (Eldaief et al., 2011; Wang et al., 2014) and the cerebellum (Halko et al., 2014). The latter study also used individual FC to choose the stimulation target.

Future studies may consider examining whether the stimulation regimen itself, largely inspired by conventional rTMS treatment for depression (George et al., 1997), where it was adopted without systematic exploration of the parameter space, is optimal, and whether even more dramatic or faster responses are attainable using optimized stimulation parameter settings.

\section{Conclusion}

The hippocampal network FC changes reported by Wang et al. (2014) after PPC rTMS are reproducible in magnitude, specificity, and topographic distribution. Our additional analyses, ruling out changes in global correlation, further strengthen the evidence for the selectivity of this approach for the hippocampal network. Moreover, our findings suggest that these effects are achievable with fewer than five stimulation sessions. This provides encouraging support for PPC rTMS as a means of enhancing memory network FC and for rTMS in general as a technique for producing targeted changes in brain network connectivity.

\section{References}

Baraduc P, Lang N, Rothwell JC, Wolpert DM (2004) Consolidation of dynamic motor learning is not disrupted by rTMS of primary motor cortex. Curr Biol 14:252-256.

Cavada C, Goldman-Rakic PS (1989) Posterior parietal cortex in rhesus monkey: I. Parcellation of areas based on distinctive limbic and sensory corticocortical connections. J Comp Neurol 287:393421.

Cox RW (1996) AFNI : software for analysis and visualization of functional magnetic resonance neuroimages. Comput Biomed Res 29:162-173.

Eldaief MC, Halko MA, Buckner RL, Pascual-Leone A (2011) Transcranial magnetic stimulation modulates the brain's intrinsic activity in a frequency-dependent manner. Proc Natl Acad Sci USA 108: 21229-21234.

George MS, Wassermann EM, Kimbrell TA, Little JT, Williams WE, Danielson AL, Greenberg BD, Hallett M, Post RM (1997) Mood improvement following daily left prefrontal repetitive transcranial magnetic stimulation in patients with depression: a placebocontrolled crossover trial. Am J Psychiatry 154:1752-1756.

Gotts SJ, Simmons WK, Milbury LA, Wallace GL, Cox RW, Martin A (2012) Fractionation of social brain circuits in autism spectrum disorders. Brain 135:2711-2725.

Gratton C, Lee TG, Nomura EM, Esposito MD, Halko MA, Israel B (2013) The effect of theta-burst TMS on cognitive control networks measured with resting state fMRI. Front Syst Neurosci 7:1-14.

Halko MA, Farzan F, Eldaief MC, Schmahmann JD, Pascual-Leone A (2014) Intermittent theta-burst stimulation of the lateral cerebellum increases functional connectivity of the default network. J Neurosci 34:12049-12056.

Héroux ME, Taylor JL, Gandevia SC (2015) The use and abuse of transcranial magnetic stimulation to modulate corticospinal excitability in humans. PLoS One 10:1-10.

Hotermans C, Peigneux P, De Noordhout AM, Moonen G, Maquet P (2008) Repetitive transcranial magnetic stimulation over the primary motor cortex disrupts early boost but not delayed gains in performance in motor sequence learning. Eur J Neurosci 28:12161221.

lezzi E, Suppa A, Conte A, Agostino R, Nardella A, Berardelli A (2010) Theta-burst stimulation over primary motor cortex degrades early motor learning. Eur J Neurosci 31:585-592.

Jung J, Bungert A, Bowtell R, Jackson SR (2016) Vertex stimulation as a control site for transcranial magnetic stimulation: a concurrent TMS/fMRI study. Brain Stimul 9:58-64.

Mesulam MM, Van Hoesen GW, Pandya DN, Geschwind N (1977) Limbic and sensory connections of the inferior parietal lobule (area $\mathrm{PG}$ ) in the rhesus monkey: a study with a new method for horseradish peroxidase histochemistry. Brain Res 136:393-414.

Muellbacher W, Ziemann U, Wissel J, Dang N, Kofler M, Facchini S, Boroojerdi B, Poewe W, Hallett M (2002) Early consolidation in human primary motor cortex. Nature 415:640-644.

Nahas ZH, George MS, Schlaepfer TE, Marcolin MA, O'Reardon JP, Padberg F, Fitzgerald PB (2008) Controversy: repetitive transcranial magnetic stimulation or transcranial direct current stimulation shows efficacy in treating psychiatric diseases (depression, mania, schizophrenia, obsessive-compulsive disorder, panic, posttraumatic stress disorder). Brain Stimul 2:14-21.

Nestor PJ, Fryer T, Hodges JR (2006) Declarative memory impairments in Alzheimer's disease and semantic dementia semantic dementia. Neuroimage 30:1010-1020.

Poldrack RA, Clark J, Paré-Blagoev EJ, Shohamy D, Moyano JC, Myers C, Gluck MA (2001) Interactive memory systems in the human brain. Nature 414:546-550.

Poldrack RA, Matthews PM, Gorgolewski KJ, Baker CI, Munafò MR, Vul E, Yarkoni T, Nichols TE, Durnez J, Poline JB (2017) Scanning the horizon: towards transparent and reproducible neuroimaging research. Nat Rev Neurosci 18:115-126.

Power JD, Barnes KA, Snyder AZ, Schlaggar BL, Petersen SE (2012) Spurious but systematic correlations in functional connectivity MRI networks arise from subject motion. Neuroimage 59:2142-2154.

Rahnev D, Kok P, Munneke M, Bahdo L, De Lange FP, Lau H (2013) Continuous theta burst transcranial magnetic stimulation reduces resting state connectivity between visual areas. J Neurophysiol 110:1811-1821.

Rastogi A, Cash R, Dunlop K, Vesia M, Kucyi A, Ghahremani A, Downar J, Chen J, Chen R (2017) Modulation of cognitive cerebello-cerebral functional connectivity by lateral cerebellar continuous theta burst stimulation. Neuroimage 158:48-57.

Rosenthal CR, Roche-Kelly EE, Husain M, Kennard C (2009) Response-dependent contributions of human primary motor cortex and angular gyrus to manual and perceptual sequence learning. J Neurosci 29:15115-15125.

Rossi S, Hallett M, Rossini PM, Pascual-Leone A; Safety of TMS Consensus Group (2009) Safety, ethical considerations, and application guidelines for the use of transcranial magnetic stimulation in clinical practice and research. Clin Neurophysiol 120:20082039.

Shirer WR, Jiang H, Price CM, Ng B, Greicius MD (2015) Optimization of rs-fMRI pre-processing for enhanced signal-noise separation, test-retest reliability, and group discrimination. Neuroimage 117: 67-79.

Steel A, Song S, Bageac D, Knutson KM, Keisler A, Saad ZS, Gotts SJ, Wassermann EM, Wilkinson L (2016) Shifts in connectivity during procedural learning after motor cortex stimulation: a combined transcranial magnetic stimulation/functional magnetic resonance imaging study. Cortex 74:134-148. 
Steinmetz H, Fürst G, Meyer BU (1989) Craniocerebral topography within the international 10-20 system. Electroencephalogr Clin Neurophysiol 72:499-506.

Talairach P, Tournoux J (1988) A stereotactic coplanar atlas of the human brain. New York: Thieme.

Teo JTH, Swayne OBC, Cheeran B, Greenwood RJ, Rothwell JC (2011) Human $\theta$ burst stimulation enhances subsequent motor learning and increases performance variability. Cereb Cortex 21: 1627-1638.

Thut G, Pascual-Leone A (2010) A review of combined TMS-EEG studies to characterize lasting effects of repetitive TMS and assess their usefulness in cognitive and clinical neuroscience. Brain Topogr 22:219-232.

Tzourio-Mazoyer N, Landeau B, Papathanassiou D, Crivello F, Etard O, Delcroix N, Mazoyer B, Joliot M (2002) Automated anatomical labeling of activations in SPM using a macroscopic anatomical parcellation of the MNI MRI single-subject brain. Neuroimage 15:273-289

Vakil E (2005) The effect of moderate to severe traumatic brain injury (TBI) on different aspects of memory: a selective review. J Clin Exp Neuropsychol 27:977-1021.

van der Werf Y, Sanz-Arigita EJ, Menning S, van den Heuvel OA (2010) Modulating spontaneous brain activity using repetitive transcranial magnetic stimulation. BMC Neurosci 11:145.
Vercammen A, Knegtering $\mathrm{H}$, Liemburg $\mathrm{E}$, den Boer A, Aleman A (2010) Functional connectivity of temporo-parietal region in schizophrenia: effects of rTMS treatment of auditory hallucinations. J Psychiatr Res 44:725-731.

Wang JX, Rogers LM, Gross EZ, Ryals AJ, Dokucu ME, Brandstatt KL, Hermiller MS, Voss JL (2014) Targeted enhancement of cortical-hippocampal brain networks and associative memory. Science 345:1054-1057.

Wang JX, Voss JL (2015) Long-lasting enhancements of memory and hippocampal-cortical functional connectivity following multipleday targeted noninvasive stimulation. Hippocampus 25:877-883.

Wilkinson L, Teo JT, Obeso I, Rothwell JC, Jahanshahi M (2010) The contribution of primary motor cortex is essential for probabilistic implicit sequence learning: evidence from theta burst magnetic stimulation. J Cogn Neurosci 22:427-436.

Wilkinson L, Steel A, Mooshagian E, Zimmermann T, Keisler A, Lewis JD, Wassermann EM (2015) Online feedback enhances early consolidation of motor sequence learning and reverses recall deficit from transcranial stimulation of motor cortex. Cortex 71:134-147.

Yeo BT, Krienen FM, Sepulcre J, Sabuncu MR, Lashkari D, Hollinshead M, Roffman JL, Smoller JW, Zöllei L, Polimeni JR, Fischl B, Liu H, Buckner RL (2011) The organization of the human cerebral cortex estimated by intrinsic functional connectivity. J Neurophysiol 106:1125-1165. 